\title{
Sexual Reproduction in Aspergillus flavus Sclerotia Naturally Produced in Corn
}

\author{
Bruce W. Horn, Ronald B. Sorensen, Marshall C. Lamb, Victor S. Sobolev, \\ Rodrigo A. Olarte, Carolyn J. Worthington, and Ignazio Carbone
}

First, second, third, and fourth authors: National Peanut Research Laboratory, United States Department of Agriculture-Agricultural Research Service, Dawson, GA; and fifth, sixth, and seventh authors: Center for Integrated Fungal Research, Department of Plant Pathology, North Carolina State University, Raleigh.

Accepted for publication 12 July 2013.

\begin{abstract}
Horn, B. W., Sorensen, R. B., Lamb, M. C., Sobolev, V. S., Olarte, R. A., Worthington, C. J., and Carbone, I. 2014. Sexual reproduction in Aspergillus flavus sclerotia naturally produced in corn. Phytopathology 104:7585.

Aspergillus flavus is the major producer of carcinogenic aflatoxins worldwide in crops. Populations of A. flavus are characterized by high genetic variation and the source of this variation is likely sexual reproduction. The fungus is heterothallic and laboratory crosses produce ascospore-bearing ascocarps embedded within sclerotia. However, the capacity for sexual reproduction in sclerotia naturally formed in crops has

and 2011 and sclerotia of A. flavus S strain were dominant in 2012. The incidence of $S$ strain sclerotia in corn ears increased with decreasing water availability. Ascocarps were not detected in sclerotia at harvest but incubation of sclerotia on the surface of nonsterile soil in the laboratory resulted in the formation of viable ascospores in A. flavus $\mathrm{L}$ and $\mathrm{S}$ strains and in homothallic A. alliaceus. Ascospores were produced by section Flavi species in $6.1 \%$ of the 6,022 sclerotia (18 of 84 ears) in $2010,0.1 \%$ of the 2,846 sclerotia ( 3 of 36 ears) in 2011 , and $0.5 \%$ of the 3,106 sclerotia (5 of 26 ears) in 2012. For sexual reproduction to occur under field conditions, sclerotia may require an additional incubation period on soil following dispersal at crop harvest.
\end{abstract} not been examined. Corn was grown for 3 years under different levels of drought stress at Shellman, GA, and sclerotia were recovered from 146 ears ( $0.6 \%$ of ears). Sclerotia of A. flavus L strain were dominant in 2010
Additional keywords: Aspergillus parasiticus, biological control, Eupenicillium ochrosalmoneum.
Aflatoxins produced by Aspergillus flavus and A. parasiticus are among the most potent carcinogens known from nature and also exhibit acutely toxic and immunosuppressive properties (57). These fungi contaminate corn, peanut, cottonseed, tree nuts, and other crops with aflatoxins in the field and during storage (34) and are responsible for major worldwide economic losses due to the costs associated with the monitoring for aflatoxins and the rejection of crops destined for human consumption and animal feed $(42,48)$. Drought and high temperatures during crop development are conducive to invasion by aflatoxigenic fungi and the production of aflatoxins (34). A. flavus is the dominant aflatoxin-producing species in most crops, whereas $A$. parasiticus is most prevalent in peanut (13).

A. flavus and A. parasiticus belong to Aspergillus section Flavi (37) and both species commonly produce sclerotia in culture (17). Two morphotypes of $A$. flavus based on sclerotium size have been designated: the large (L) strain, with sclerotia $>400 \mu \mathrm{m}$ in diameter, and the small (S) strain, with numerous sclerotia of $<400 \mu \mathrm{m}$ (4). Sclerotium formation has been reported in corn by A. flavus L strain (51,52), in cottonseed by A. flavus S strain (10), and in peanut by $A$. parasiticus (15). A. flavus sclerotia produced on corn in southern Georgia were shown to be dispersed onto the soil surface during combine harvesting (52). Dispersal of $A$. flavus sclerotia was accompanied by dispersal of sclerotia of Eupenicillium ochrosalmoneum, a homothallic fungus responsible

Corresponding author: B. W. Horn; E-mail address: bruce.horn@ars.usda.gov

http://dx.doi.org/10.1094/PHYTO-05-13-0129-R

This article is in the public domain and not copyrightable. It may be freely reprinted with customary crediting of the source. The American Phytopathological Society, 2014 for the production of neurotoxic citreoviridin in corn (53). Sclerotia of E. ochrosalmoneum did not contain ascospores at the time of dispersal (52). However, Horn and Wicklow (23) showed that incubation of E. ochrosalmoneum sclerotia from corn on the soil surface results in the formation of ascospores.

Fungal sclerotia are considered to be resistant structures designed to withstand adverse environmental conditions (3). In addition to their role as survival structures, sclerotia of $A$. flavus and $A$. parasiticus germinate sporogenically on soil by producing aerial conidiophores $(50,54)$. It has been postulated that sporogenically germinating sclerotia are a source of primary inoculum in crops (50). However, the role of sclerotia in the life cycle of $A$. flavus, A. parasiticus, and related $A$. nomius has been recently reassessed with the discovery of the sexual stage associated with these structures $(18,19,21,22)$. A. flavus and A. parasiticus are heterothallic and strains typically contain one of two mating-type genes, MAT1-1 and MAT1-2 (39). Laboratory crosses between strains of the opposite mating type result in the production of ascospore-bearing ascocarps that are embedded within the matrix of sclerotia. Sexual reproduction in A. flavus and A. parasiticus produces recombinant progeny through the independent assortment of chromosomes and through crossing over within the aflatoxin gene cluster as well as other portions of the genome $(2,22$, 31,33). Recombination likely accounts for the high genetic variation in field populations of A. flavus (33), in which strains range in toxigenicity from nonaflatoxigenic to potent producers of aflatoxins $(14,17)$. Because sclerotia from section Flavi act as a repository for sexual structures, they are more appropriately referred to as stromata (22). However, sclerotia lacking a sexual stage are produced by unmated single strains and, to varying degrees, by sexually compatible crosses $(18,22,33)$. To avoid confusion in terminology, in the present article, these structures in 
section Flavi species and E. ochrosalmoneum will be called sclerotia regardless of the presence of a sexual stage.

Although sclerotia of E. ochrosalmoneum form a sexual stage on soil following dispersal from corn, nothing is known about the capacity of $A$. flavus and $A$. parasiticus sclerotia from crops to produce ascospores. In this study, sclerotia of A. flavus were produced in culture from crosses and were harvested before ascocarp formation. Sexual reproduction in these sclerotia was examined under laboratory conditions by incubating sclerotia on the surface of nonsterile soil or when buried in soil. Sclerotia from section Flavi also were collected for 3 years (2010 to 2012) from corn grown in the field under different levels of drought stress. Using the laboratory conditions previously determined to be conducive to ascospore formation, naturally produced sclerotia were incubated on the surface of nonsterile soil to assess their capacity for sexual reproduction.

\section{MATERIALS AND METHODS}

Sexual crosses and sclerotium production. A. flavus L strains of the opposite mating type (MAT1-1 and MAT1-2) were crossed to produce sclerotia for comparing ascospore formation under laboratory conditions on culture slants and on the soil surface or when buried in soil. Crosses were performed using highly fertile strain combinations, as previously determined $(18,33)$ (B. W. Horn, unpublished data) (Table 1). All crosses involved strains belonging to different vegetative compatibility groups and four of the crosses included commercially available biological control strains NRRL 21882 and AF36 (6). Slants containing mixed cereal agar (MCA) (30) were inoculated with conidial suspensions of paired strains and incubated in darkness at $30^{\circ} \mathrm{C}$ for 2 weeks (22). Sclerotia which had not yet formed ascocarps were removed from slants by scraping in distilled water containing Tween 20 at $50 \mu \mathrm{l} /$ liter and were cleaned by filtering, vortexing in water with glass beads, and rinsing repeatedly with water (22). The air-dried sclerotia were stored in a desiccator jar over saturated $\mathrm{NaCl}$ solution at $25^{\circ} \mathrm{C}(75 \%$ relative humidity). Additional MCA slant cultures were used for continued incubation at $30^{\circ} \mathrm{C}$ in sealed plastic bags (22).

Incubation of laboratory-produced sclerotia. A. flavus sclerotia on MCA slants and on the surface of soil were examined at the start of the experiment (2 weeks following inoculation of MCA slants, when sclerotia were harvested) and after 4, 8, 12, and 16 weeks additional incubation; sclerotia buried in soil were examined only after 16 weeks. For MCA slant cultures, sclerotia from three replicate slants per cross were harvested at 4-week intervals and 100 sclerotia per slant were dissected with a microscalpel for the presence of ascocarps and ascospores (22).

Soil incubation experiments were conducted using soil with native microbial populations obtained from a cornfield in Shellman, GA, where most of the naturally produced sclerotia were obtained (see below). The soil was air dried to $1.6 \pm 0.01 \%$ moisture ( \pm standard deviation, $n=3$; dry weight basis) and sieved through Number 12 and 20 Standard Testing Sieves in tandem. Distilled water was added to sieved soil $(14 \mathrm{ml}$ per $100 \mathrm{~g}$ of soil) and the soil was allowed to equilibrate in sealed containers overnight. Moistened soil was added to the rim of $30-\mathrm{cm}^{3}$ graduated plastic medicine cups for surface incubation of sclerotia obtained from MCA slants. For buried sclerotia, $25 \mathrm{~cm}^{3}$ of soil was added to cups, sclerotia were sprinkled on the soil surface, and an additional $5 \mathrm{~cm}^{3}$ of soil was placed over the sclerotia. In total, $\approx 250$ to 350 sclerotia from each cross (Table 1) were added to each of three replicate cups. Soil cups were incubated in darkness in a desiccator jar over distilled water at $30^{\circ} \mathrm{C}(100 \%$ relative humidity). Fifty sclerotia per cup were randomly removed from the soil surface at each time interval and dissected. Buried sclerotia were retrieved after 16 weeks by wet sieving the top $10 \mathrm{~cm}^{3}$ of soil in cups through a 100-mesh filter. Viability of buried sclerotia was determined by vortexing sclerotia for $30 \mathrm{~s}$ in distilled water with glass beads and surface sterilizing for $2 \mathrm{~min}$ with $0.25 \%$ sodium hypochlorite followed by several sterile water rinses. Sclerotium halves resulting from the dissection of 20 sclerotia without ascocarps per cup were plated on Czapek agar (CZ) with antibiotics (streptomycin at $30 \mathrm{mg} /$ liter and chlortetracycline at $1.5 \mathrm{mg} / \mathrm{liter}$ ).

Experiments involving sexual reproduction in laboratoryproduced sclerotia on MCA slants, on the soil surface, and buried in soil were performed twice.

Corn cultivation. Naturally produced sclerotia from section Flavi were obtained from corn grown in experimental plots at Shellman, GA, in 2010 to 2012 in conjunction with a long-term project by the National Peanut Research Laboratory on water-use efficiency (28). Soil consisted of Greenville fine sandy loam (fine, kaolinitic, thermic Rhodic Kandiudults). Corn was planted and harvested on 6 April and 12 August 2010 (hybrid Pioneer P33M53), 15 March and 18 August 2011 (Pioneer P1814HR), and 22 March and 14 August 2012 (Pioneer P1456HR), respectively. Corn was grown under conventional tillage in a randomized complete block design consisting of four overhead irrigation treatments with three plots per treatment (28). Each plot consisted of 18 rows of corn planted $0.9 \mathrm{~m}$ apart and $30.5 \mathrm{~m}$ in length. The treatments provided different levels of drought stress in corn: 0\% irrigation (dry land cultivation) and 33,66 , and $100 \%$ of the overhead irrigation rate recommended by Irrigation Pro for Corn software (http://www.ars. usda.gov/services/software/download.htm?softwareid=248). Rainfall and air temperature were recorded from an onsite electronic weather station and grain yield was determined from the four center rows of each plot $(28,45)$. For measuring aflatoxin concentrations, a 2-kg subsample from the thoroughly mixed grain-yield sample was ground in a Romer Series II Mill (Romer Labs, Inc., Union, MO); $200 \mathrm{~g}$ of ground corn was extracted and analyzed for aflatoxins by high-performance liquid chromatography according to Sobolev and Dorner (44).

Sclerotia from corn. Preliminary examination of 500 randomly collected corn ears from Shellman indicated that sclerotia were present primarily in ears with visible sporulation by section

TABLE 1. Aspergillus flavus crosses for producing sclerotia ${ }^{\mathrm{a}}$

\begin{tabular}{|c|c|c|c|c|c|c|}
\hline \multicolumn{3}{|c|}{ MAT1-1 } & & \multicolumn{3}{|c|}{ MAT1-2 } \\
\hline Strain & VCG & Aflatoxins & & Strain $^{\mathrm{b}}$ & VCG & Aflatoxins \\
\hline 29473 & 17 & + & $x$ & 29487 & 25 & + \\
\hline 29537 & 63 & + & $x$ & 29536 & 62 & + \\
\hline 29473 & 17 & + & $x$ & 21882 & 24 & - \\
\hline 29507 & 33 & + & $x$ & AF36 & YV36 & - \\
\hline 29473 & 17 & + & $x$ & AF36 & YV36 & - \\
\hline
\end{tabular}

a Mating-type designations (MAT) are from Ramirez-Prado et al. (39). Strain numbers (except AF36) are from Agricultural Research Service Culture Collection (NRRL), Peoria, IL. Vegetative compatibility groups (VCGs) are based on Horn and Greene (16), except for YV36 (9). Aflatoxin production is from Horn et al. (17).

b Biological control strains are NRRL 21882 (Afla-Guard) and AF36 (= NRRL 18543) (6). 
Flavi species; therefore, only ears showing sporulation were handharvested for sclerotia. All ears from three randomly selected rows in each of three replicate plots per irrigation treatment were examined at harvest for visible section Flavi. In addition to the experimental plots at Shellman, 8 to 32 ears with visible section Flavi were collected from four other nonirrigated cornfields in 2010: field A (1.1 km southeast of Shellman, Randolph County, GA), field B (4.8 km northwest of Dawson, Terrell County, GA), field C (6.4 km south of Shellman, Randolph County, GA), and field D (12 km southeast of Rocky Mount, Edgecombe County, North Carolina).

Corn ears were dried at ambient temperature on a forced-air dryer, and kernels from up to three regions with visible section Flavi on each ear were dissected and examined externally and internally for sclerotia under the stereomicroscope. Sclerotia from each ear were vortexed for $20 \mathrm{~s}$ in $10 \mathrm{ml}$ of distilled water without beads, filtered, placed on the surface of nonsterile soil from Shellman in medicine cups, and incubated in darkness in a desiccator jar over distilled water for 5 to 7 months $\left(30^{\circ} \mathrm{C}, 100 \%\right.$ relative humidity). Following incubation, sclerotia were cleaned and surface sterilized as previously described for buried sclerotia. Species were identified from 20 sclerotia (when available) by transferring to $\mathrm{CZ}$ plates with antibiotics, the sclerotium halves resulting from dissections or, in some cases, conidia produced by sclerotia through sporogenic germination or ascospore masses from ascocarps.

Viability of ascospores was determined for individual ascocarps (one ascocarp per sclerotium) from Shellman experimental plots and the additional fields A, C, and D in 2010 (105 ascocarps of $A$. flavus L strain and 6 ascocarps of A. alliaceus, distributed among 23 ears), from Shellman in 2011 (1 ascocarp of A. flavus S strain), and from Shellman in 2012 (3 ascocarps of A. flavus S strain and 1 ascocarp of $A$. flavus $\mathrm{L}$ strain, distributed among 4 ears). Ascospores were dilution plated onto malt extract agar with antibiotics and examined for germination with the microscope; germlings were then subcultured to $\mathrm{CZ}$ plates (22).

Statistics. Student's $t$ test was performed on each cross to compare percentages of sclerotia forming ascospores on slant cultures and on the soil surface ( $n=3$ slants or soil cups) after 16 weeks of incubation and to compare percentages of sclerotia forming ascospores on the soil surface and when buried in soil $(n=3$ soil cups) after 16 weeks. The $t$ test also was used on each cross to compare percent ascospore formation in sporogenic and nonsporogenic sclerotia ( $n=3$ soil cups) but tests were based on combined totals of sclerotia sampled from each cup after maximum ascospore formation (8, 12, and 16 weeks of incubation). A one-way analysis of variance and Student-Newman-Keuls test for multiple comparison of means were performed to compare July temperatures for 2010-2012 ( $n=30$ or 31 days) in the cornfield at Shellman. Coefficients of determination $\left(R^{2}\right)$ for linear regressions were determined to examine the effect of water availability in corn for each year on grain yield, aflatoxin concentration, and percentage of ears with either section Flavi sporulation or sclerotia; regressions were based on individual plots $(n=12$ in 2010 and 2012; $n=9$ in 2011). All statistics were performed with SigmaStat (version 3.5; Jandel Scientific, San Rafael, CA).

\section{RESULTS}

Ascospore formation and sporogenic germination in sclerotia from laboratory crosses. A. flavus sclerotia were produced on MCA slants using six sexually compatible crosses (Table 1). Ascocarp or ascospore formation was compared between sclerotia left on MCA slants and sclerotia harvested from MCA slants before ascocarp formation and then incubated on the surface of nonsterile soil. Although sclerotia did not contain ascocarps at the beginning of the experiments, ascocarps and ascospores formed readily thereafter on both MCA slants and the soil surface (Fig. 1). After 4 weeks of incubation on MCA slants and soil, ascocarps contained asci with mostly immature ascospores; ascocarps after 8 weeks of incubation contained predominantly free mature ascospores following breakdown of the ascus walls. Sclerotia differed in the incidence of ascospore formation according to the specific cross. For example, percent ascospore formation in NRRL $29473 \times 29487$ and NRRL $29473 \times 21882$ sclerotia was relatively low $(\leq 50 \%)$ after 16 weeks of incubation on both MCA slants and the soil surface in experiments 1 and 2 and was consistently high $(>60 \%)$ in NRRL $29473 \times$ AF36 sclerotia (Fig. 1). Percent ascospore formation in NRRL $29473 \times 29487$ and NRRL $29507 \times 21882$ sclerotia after 16 weeks was significantly higher $(P<0.05)$ on soil compared with MCA slants in both experiments. Sclerotia from NRRL $29507 \times$ AF36 were inconsistent in percent ascospore formation between experiments (significantly lower $[P<0.001]$ on soil compared with slants only in experiment 2); NRRL $29537 \times 29536$, NRRL $29473 \times 21882$, and NRRL $29473 \times$ AF36 sclerotia showed no significant differences $(P>0.05)$ in percent ascospore formation between MCA slants and the soil surface in either experiment after 16 weeks.

Sclerotia of A. flavus on the soil surface often germinated sporogenically (Fig. 2A). Sporogenic germination varied according to the cross. Sclerotia from some crosses were predominantly nonsporogenic (NRRL $29507 \times 21882$ and NRRL $29473 \times$ 21882) and sclerotia from other crosses were lightly sporogenic with only a few conidiophores per sclerotium (NRRL $29473 \times$ 29487, NRRL $29537 \times 29536$, and NRRL $29507 \times$ AF36) or were heavily sporogenic with dense sporulation on the sclerotium surface (NRRL $29473 \times$ AF36). Sporogenic germination did not occur with every sclerotium on the soil surface (Fig. 2A). A comparison of ascospore formation in sporogenic and nonsporogenic sclerotia from four crosses showed a significantly lower $(P<$ $0.05)$ incidence of ascospore formation in sporogenic sclerotia from all crosses in both experiments (Fig. 3).

Sclerotia buried in soil for 16 weeks showed reduced ascospore formation compared with sclerotia incubated on the soil surface (Fig. 4). Differences were significant $(P<0.05)$ for sclerotia from all crosses in both experiments, although incidences of ascospore formation in buried sclerotia were often higher in experiment 2. Viability of buried sclerotia without ascocarps among crosses was 1.1 to $31.8 \%$ in experiment 1 and 90.0 to $100 \%$ in experiment 2 .

Effects of drought stress in corn. Corn was grown in experimental plots at Shellman, GA, under different drought stress conditions by supplementing rainfall with varying amounts of water from overhead irrigation (Table 2). Average minimum air temperature and average daily temperature were both significantly higher $(P<0.05)$ in 2010 compared with 2011 and 2012 for July when corn kernels were in late stages of maturation; average July maximum air temperatures were not significantly different among the 3 years. The differences in July temperature also were reflected by the higher number of days in 2010 compared with 2011 and 2012 in which the temperature was $>37^{\circ} \mathrm{C}$ (Table 2). Rainfall during July was lowest in 2010 for the 3 -year period.

The present research was ancillary to the long-term corn project on water-use efficiency at Shellman, in which a different corn hybrid was planted for each of the 3 years. Because of the possible hybrid effect, the effects of water availability on corn yield, aflatoxin concentration, and fungal incidence were statistically compared only within individual years. Increasing water availability in corn associated with irrigation led to a significant increase $(P<0.001)$ in grain yield in $2010\left(R^{2}=0.91\right), 2011\left(R^{2}=\right.$ $0.87)$, and $2012\left(R^{2}=0.83\right)$ (Table 3$)$. The $0 \%$ irrigation treatment in 2011 did not produce corn ears due to extreme drought conditions in May $(0.4 \mathrm{~cm}$ rainfall) and June $(2.8 \mathrm{~cm})$. Increasing water availability also showed a significant decrease in aflatoxin concentration in $2010\left(R^{2}=0.38 ; P=0.03\right)$ and $2012\left(R^{2}=0.32\right.$; $P=0.05)$ but not in $2011\left(R^{2}=0.07 ; P=0.49\right)$. Water availability showed no significant effect $(P>0.05)$ for any of the 3 years on percentage of ears with section Flavi sporulation $\left(R^{2}=0.17\right.$ to 
$0.30)$, percentage of ears with section Flavi sclerotia $\left(R^{2}=0.09\right.$ to $0.31)$, or percentage of ears with A. flavus L strain sclerotia $\left(R^{2}=\right.$ 0.004 to 0.31 ) (Tables 3 and 4).

Sclerotium production in corn. Dissection of corn ears revealed section Flavi sclerotia on the outer kernel surface, inside the kernel when damaged by insects (Fig. 2B), and at the base of kernels where attached to the cob. Percentages of ears with section Flavi sporulation (0.3 to $10.0 \%$ ) and sclerotia (0 to $2.5 \%$ ) in experimental plots were low for all 3 years (Table 3 ). The majority of sclerotia were produced by A. flavus L strain in 2010 and 2011 and by A. flavus S strain in 2012 (Table 4). A. flavus S strain sclerotia from combined years were detected in 27 ears, of which $51.9,29.6,18.5$, and $0.0 \%$ were from the $0,33,66$, and $100 \%$ irrigation treatments, respectively $\left(R^{2}=0.99 ; P=0.007\right)$. Sclerotia from other section Flavi species included those of $A$. parasiticus (four ears), A. alliaceus (two ears), and A. caelatus (one ear). The four additional fields from 2010 (Table 5) showed a predominance of $A$. flavus L strain sclerotia, with only two ears containing sclerotia of the $\mathrm{S}$ strain. Sclerotia of A. flavus $\mathrm{S}$ strain and $A$. parasiticus frequently co-occurred on the same ear with sclerotia of A. flavus L strain (Tables 4 and 5). Ascocarps and ascospores were not present in A. flavus sclerotia ( $n=1226$, dis-

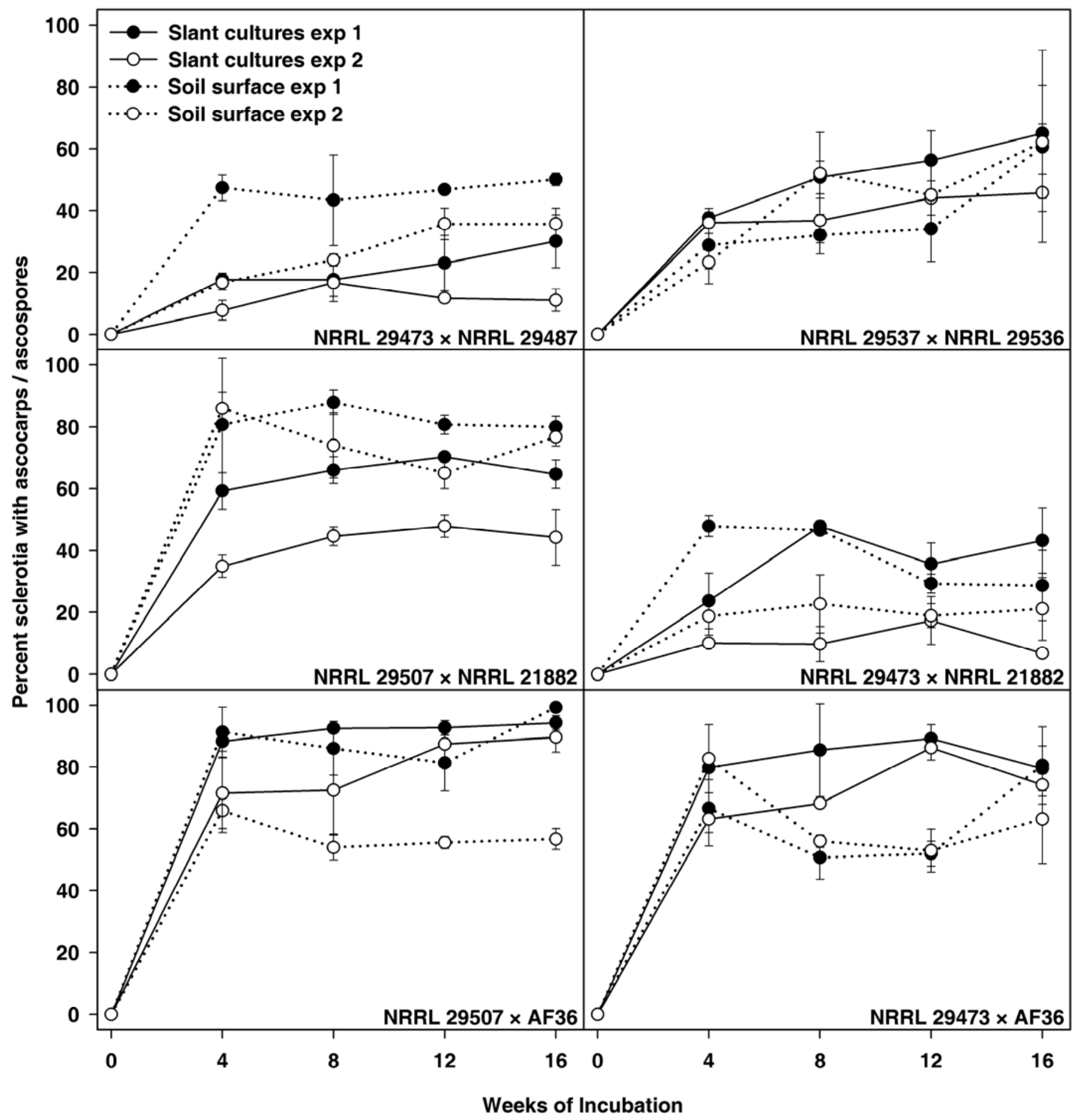

Fig. 1. Ascocarp and ascospore formation in Aspergillus flavus sclerotia incubated on mixed cereal agar slants and on the surface of nonsterile soil. Sclerotia were obtained from laboratory crosses. Ascocarps contained asci with mostly immature ascospores after 4 weeks of incubation and contained predominantly free mature ascospores at 8 weeks. Datum points represent means \pm standard deviation of three slants or soil cups; results are shown for two experiments. 

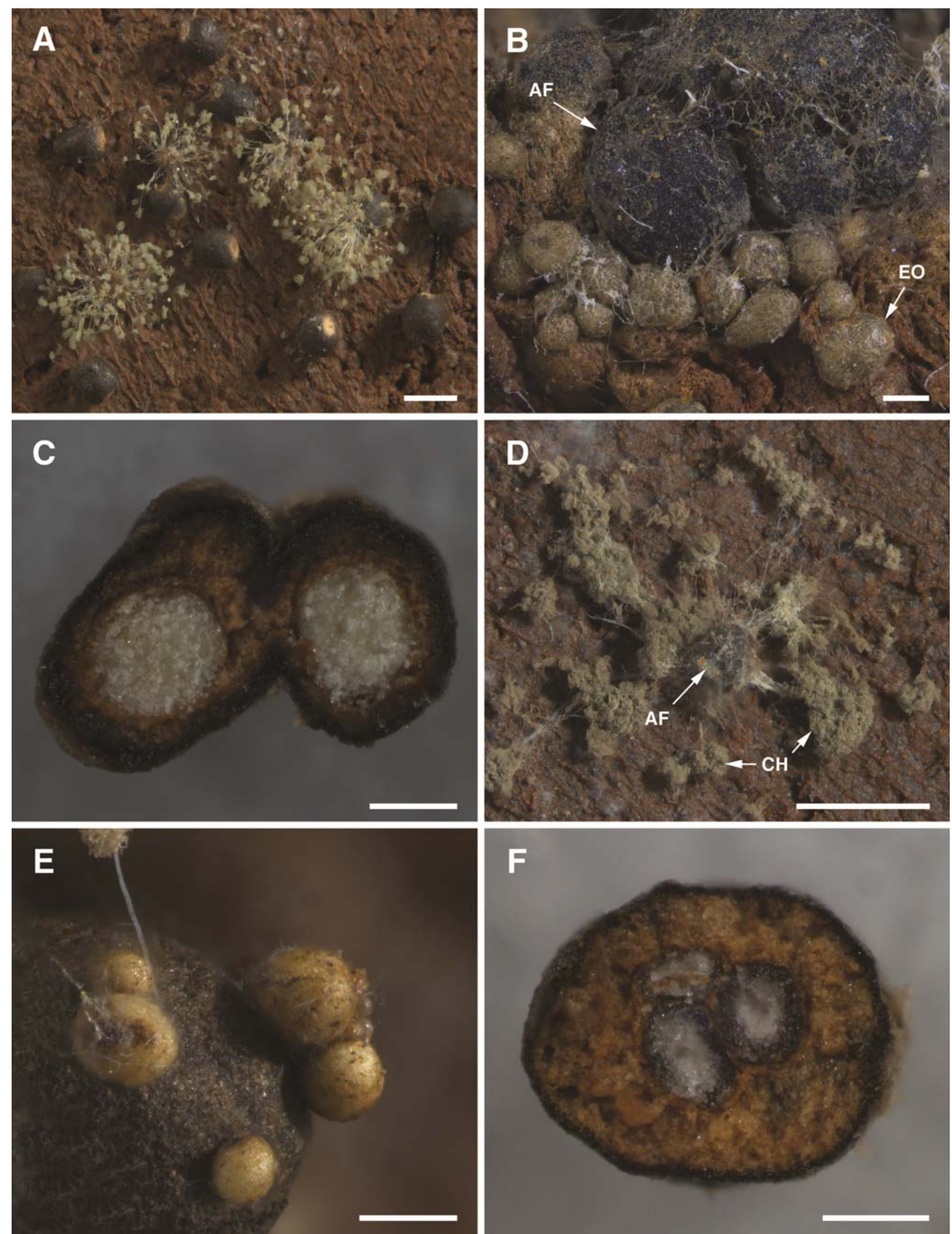

Fig. 2. Reproductive structures associated with sclerotia of Aspergillus flavus and Eupenicillium ochrosalmoneum. A, Sclerotia of A. flavus showing sporogenic germination; sclerotia were obtained from culture (NRRL $29473 \times$ AF36) and incubated on nonsterile soil. B, Sclerotia of A. flavus (AF) and E. ochrosalmoneum (EO) co-occurring inside an insect-damaged corn kernel. C, Sectioned fused pair of A. flavus sclerotia containing ascospore-filled ascocarps; sclerotia were naturally produced in corn and incubated on nonsterile soil. D, Sporogenic germination of an A. flavus sclerotium (AF) in which the conidial heads (CH) on the collapsed conidiophores have been colonized by E. ochrosalmoneum; sclerotium was obtained from corn and incubated on nonsterile soil. E, Sclerotium of A. flavus in which smaller E. ochrosalmoneum sclerotia have formed externally; A. flavus sclerotium was obtained from corn and incubated on nonsterile soil. F, Sectioned A. flavus sclerotium containing three ascospore-bearing sclerotia of E. ochrosalmoneum; A. flavus sclerotium was obtained from corn and incubated on nonsterile soil. Scale bars $=1,000 \mu \mathrm{m}$ for A and D and $200 \mu \mathrm{m}$ for B, C, E, and F. 
tributed among 58 ears) and A. alliaceus sclerotia ( $n=11$, distributed among 2 ears) when examined directly from corn ears at harvest.

Ascospore formation in sclerotia from corn. When section Flavi sclerotia collected from Shellman corn were incubated on the surface of nonsterile soil under laboratory conditions, ascospore formation was observed in $6.1 \%$ of the 6,022 sclerotia (18 of 84 ears) in $2010,0.1 \%$ of the 2,846 sclerotia ( 3 of 36 ears) in 2011 , and $0.5 \%$ of the 3,106 sclerotia (5 of 26 ears) in 2012 (Fig. $2 \mathrm{C}$; Table 4). The majority of sclerotia that were fertile (formed ascospores) belonged to A. flavus L strain (Table 4). Fertile sclerotia of $A$. flavus $\mathrm{S}$ strain were detected in $2011(n=1)$ and 2012 ( $n=9$, distributed among three ears) and highly fertile sclerotia of homothallic A. alliaceus were detected in $2010(n=$ 114 , distributed among two ears). In individual ears containing exclusively A. flavus L strain sclerotia, fertility ranged from $0.3 \%$ $(n=318)$ to $34.6 \%(n=26)$ (Table 4). Fertile sclerotia of $A$. flavus $\mathrm{L}$ strain were obtained from ears from all irrigation treatments in 2010 as well as from three of the four additional fields (Tables 4 and 5); incidences of ears with fertile sclerotia from irrigation treatments in 2011 and 2012 were very low. Ascospore germination and subsequent colony growth occurred in all ascocarps of A. flavus $\mathrm{L}$ and $\mathrm{S}$ strains and A. alliaceus from the Shellman experimental plots and the additional fields A, C and D.

E. ochrosalmoneum sclerotia in corn. During dissection of corn ears, E. ochrosalmoneum was often observed sporulating on corn kernels as well as on the conidial heads of section Flavi. E. ochrosalmoneum produced small sclerotia inside insect-damaged kernels, where they occasionally co-occurred with sclerotia of $A$. flavus (Fig. 2B). Ascospores were not observed in E. ochro-

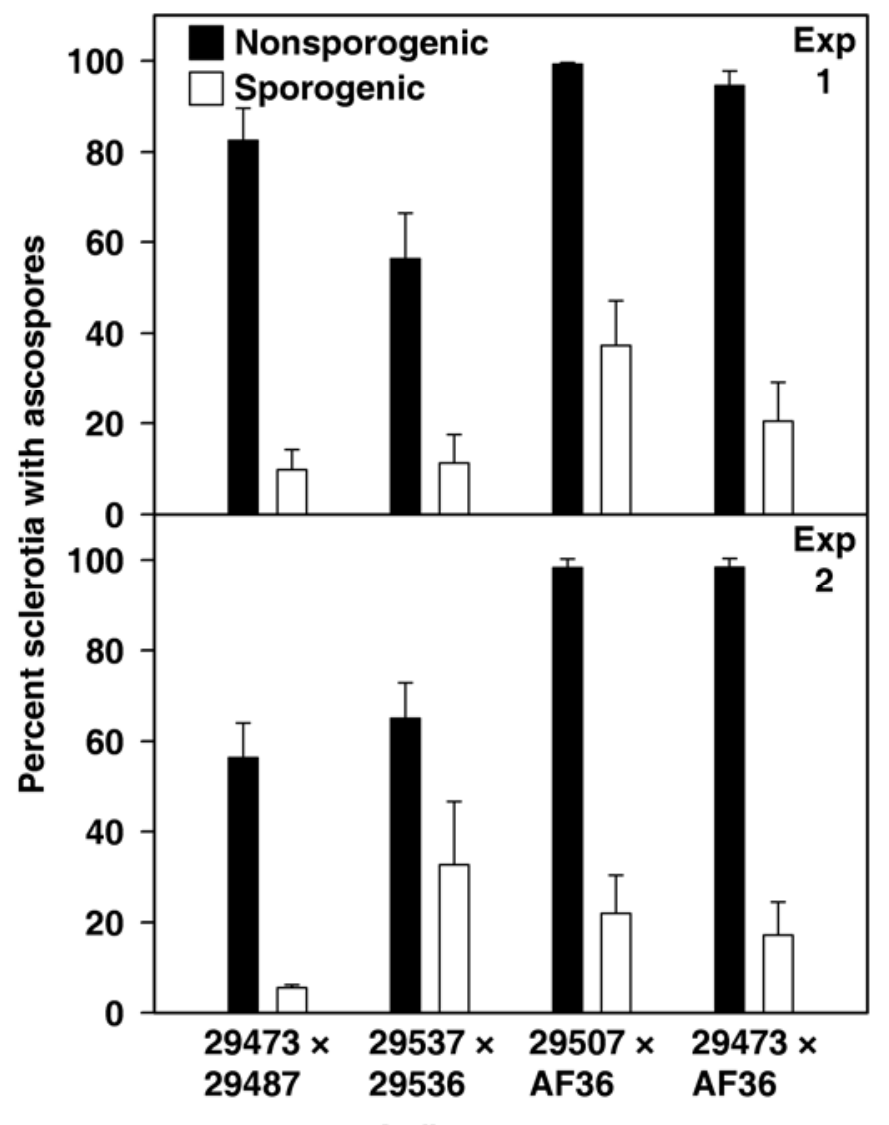

A. flavus crosses

Fig. 3. Percent ascospore formation in Aspergillus flavus sclerotia with and without sporogenic germination on nonsterile soil after 16 weeks of incubation. Sclerotia were obtained from laboratory crosses. Bars represent means \pm standard deviation of three soil cups; results are shown for two experiments. salmoneum sclerotia ( $n=772$, distributed among 16 ears) from corn ears at harvest but $48.8 \%$ of the sclerotia $(n=467$, distributed among 14 ears) formed ascospores after incubation on the surface of nonsterile soil. In addition, incubation of $A$. flavus sclerotia on soil often resulted in sporulation by $E$. ochrosalmoneum on the sclerotium surface or in instances of sporogenic germination on the conidial heads produced by A. flavus (Fig. 2D). Ascospore-bearing sclerotia of E. ochrosalmoneum also were observed on the surface of A. flavus sclerotia (Fig. 2E) as well as within the matrix of A. flavus sclerotia, where they resembled the ascocarps of A. flavus (Fig. 2F).

\section{DISCUSSION}

Sclerotia from A. flavus $\mathrm{L}$ and $\mathrm{S}$ strains, A. alliaceus, and E. ochrosalmoneum from corn grown under different levels of drought stress showed no evidence of sexual reproduction at corn harvest. However, subsequent incubation of sclerotia on the surface of nonsterile soil under laboratory conditions conducive to sexual reproduction, as determined by experiments using sclerotia produced from laboratory crosses, resulted in the formation of ascospore-bearing ascocarps in some of the sclerotia. This suggests that sclerotia may require an additional incubation period on soil for sexual reproduction following dispersal from corn at harvest.

A. flavus sclerotia produced from laboratory crosses generally showed similar rates of ascocarp and ascospore formation when left in culture and when detached from the parent mycelium before ascocarp formation and placed on the surface of nonsterile soil. In both instances, ascocarps were first observed after 4 weeks of incubation and free mature ascospores were present in ascocarps after 8 weeks, which is considerably shorter than previous incubation times of 6 to 11 months (18). Therefore, the procedure for incubating sclerotia on nonsterile soil at $30^{\circ} \mathrm{C}$ and $100 \%$ relative humidity was appropriate for testing the ability of naturally formed sclerotia in corn to develop the sexual stage.

Sclerotia of A. flavus are produced by single strains as well as by crossed pairs of sexually compatible strains $(17,18,33)$, and sclerotia from both sources are capable of germinating sporo-

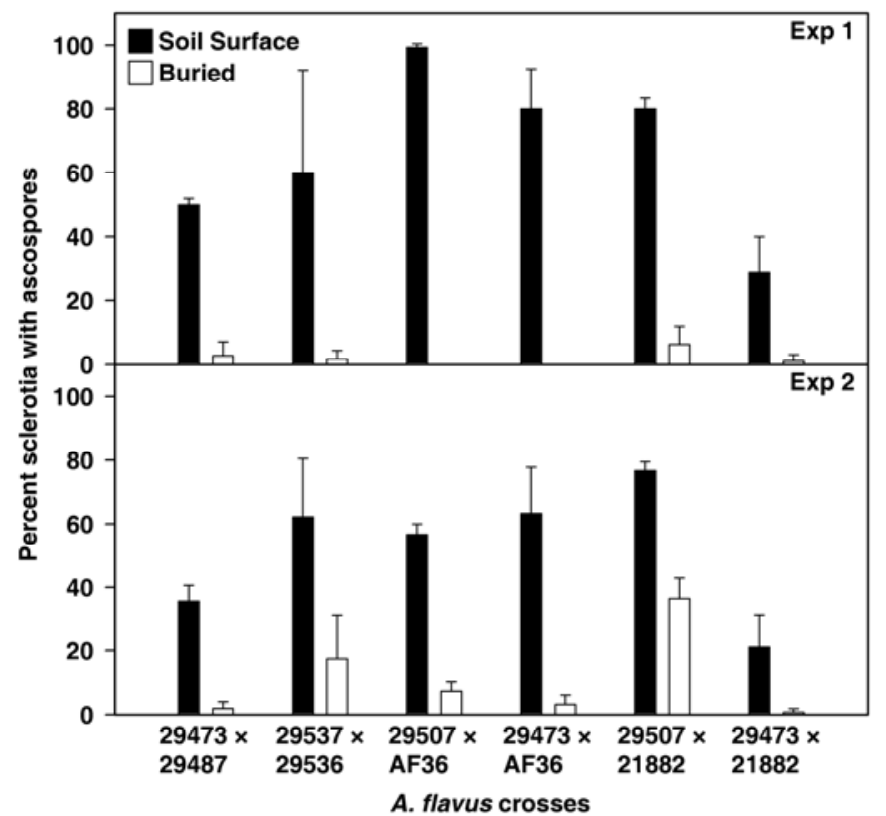

Fig. 4. Percent ascospore formation in Aspergillus flavus sclerotia incubated for 16 weeks on the surface of nonsterile soil or when buried in soil. Sclerotia were obtained from laboratory crosses. Bars represent means \pm standard deviation of three soil cups; results are shown for two experiments. 
genically. In this study, sporogenic germination often occurred in sclerotia incubated on the soil surface and depended upon the cross from which the sclerotia were derived. Wicklow and Donahue (50) also found variation in sporogenic germination in A. flavus and A. parasiticus, with sclerotia of some strains readily germinating and sclerotia of other strains not germinating or producing aerial mycelium only. Considerable variation in sporogenic germination also was observed when sclerotia from a single A. flavus strain were placed on the soil surface for 3 months in two Georgia cornfields (54). Microclimatic differences at the soil surface within a field could have been responsible for some of this variation. In this study, sporogenic germination in A. flavus sclerotia from crosses was associated with greatly reduced incidences of ascospore formation. Although the mechanism of mating with respect to sclerotium development is not known, it is possible that unfertilized sclerotia have a greater capacity for sporogenic germination, which is suggested by the presence of sporogenic and nonsporogenic sclerotia in close proximity on soil under the controlled conditions of this study. Alternatively, sclerotium reserves necessary to support sporogenic germination may preclude the development of a sexual stage in fertilized sclerotia.

Burial of A. flavus sclerotia significantly inhibited ascocarp formation, although inhibition was greater in experiment $1 \mathrm{com}-$ pared with experiment 2 . Horn and Wicklow (23) similarly showed that sclerotia of E. ochrosalmoneum readily produced ascospores on the surface of nonsterile soil and that ascospore formation was completely inhibited when sclerotia were buried. Viability of buried A. flavus sclerotia paralleled the differences between experiments in ascocarp formation, with sclerotia in experiment 1 showing both low viability and low incidence of ascocarp formation relative to experiment 2; the factors responsible for differences between experiments are not understood. When sclerotia of four strains each of $A$. flavus and A. parasiticus were buried for 36 months in Illinois and Georgia fields, 68 to $100 \%$ of sclerotia appeared viable when plated on agar medium yet failed to germinate sporogenically when incubated on the surface of moist sand (55). In contrast, Wicklow (49) showed that, under laboratory conditions, sclerotia buried in soil saturated with water to field capacity had a viability of only $2 \%$ after 26 weeks of incubation. Saturated soil with low oxygen availability reduces sclerotium viability in fungi (56) and may also inhibit the formation of the sexual stage in A. flavus.

Drought and high temperatures are associated with increased A. flavus infection and aflatoxin production in corn $(26,35,36)$, and corn kernels are most susceptible to invasion by $A$. flavus and aflatoxin accumulation during late stages of maturity $(36,47)$. Those late developmental stages in corn occurred during July at the experimental plots in Shellman. Decreasing water availability in the irrigation treatments resulted in a significant decrease in

TABLE 2. Temperature, rainfall, and irrigation applications during corn ear development at Shellman, GA

\begin{tabular}{|c|c|c|c|c|c|c|c|c|}
\hline \multirow[b]{2}{*}{ Year, month } & \multicolumn{3}{|c|}{ Air temperature $\left({ }^{\circ} \mathrm{C}\right)^{\mathrm{a}}$} & \multirow[b]{2}{*}{ Days $>37^{\circ} \mathrm{C}^{\mathrm{c}}$} & \multicolumn{4}{|c|}{ Supplemental irrigation $(\mathrm{cm})^{\mathrm{b}}$} \\
\hline & Minimum & Maximum & Average daily & & Rain $(\mathrm{cm})(0 \%)^{\mathrm{d}}$ & $33 \%$ & $66 \%$ & $100 \%$ \\
\hline \multicolumn{9}{|l|}{2010} \\
\hline June & $22.4 \pm 1.3$ & $35.1 \pm 2.1$ & $27.5 \pm 1.9$ & 7 & 8.5 & 6.1 & 12.4 & 18.5 \\
\hline July & $22.9 \pm 1.5$ & $35.7 \pm 2.8$ & $28.4 \pm 1.9$ & 10 & 8.2 & 1.7 & 3.4 & 5.1 \\
\hline August & $22.6 \pm 1.3$ & $37.6 \pm 5.9$ & $27.7 \pm 2.4$ & 9 & 15.4 & 0.0 & 0.0 & 0.0 \\
\hline \multicolumn{9}{|l|}{2011} \\
\hline June & $21.5 \pm 1.1$ & $36.8 \pm 1.7$ & $28.2 \pm 1.7$ & 16 & 2.8 & 8.5 & 13.7 & 18.8 \\
\hline July & $22.1 \pm 0.8$ & $34.5 \pm 2.2$ & $27.1 \pm 1.6$ & 2 & 15.3 & 1.7 & 3.4 & 5.1 \\
\hline August & $22.3 \pm 1.3$ & $35.8 \pm 1.4$ & $27.9 \pm 1.2$ & 5 & 5.4 & 0.0 & 0.0 & 0.0 \\
\hline \multicolumn{9}{|l|}{$2012^{\circ}$} \\
\hline June & $19.4 \pm 1.9$ & $31.5 \pm 3.7$ & $25.0 \pm 2.3$ & 2 & 6.3 & 5.3 & 10.8 & 16.1 \\
\hline July & $21.9 \pm 0.9$ & $35.3 \pm 2.1$ & $27.3 \pm 1.5$ & 5 & 10.8 & 0.0 & 0.0 & 0.0 \\
\hline August & $21.1 \pm 1.6$ & $31.9 \pm 2.2$ & $25.4 \pm 1.3$ & 1 & 5.6 & 0.0 & 0.0 & 0.0 \\
\hline
\end{tabular}

a Temperatures are means \pm standard deviation $(n=26$ to 31$)$ and are based on daily values.

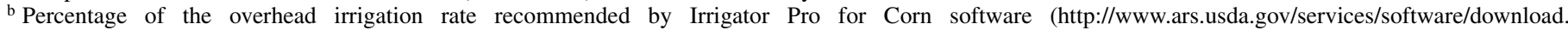
htm?softwareid=248).

c Number of days maximum air temperature $>37^{\circ} \mathrm{C}$.

d Rainfall with $0 \%$ supplemental irrigation.

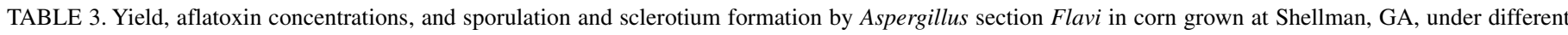
conditions of water availability ${ }^{\mathrm{a}}$

\begin{tabular}{|c|c|c|c|c|c|}
\hline \multirow[b]{2}{*}{ Irrigation treatment ${ }^{\mathrm{b}}$} & \multirow[b]{2}{*}{ Grain yield (t/ha) } & \multirow[b]{2}{*}{ Total aflatoxin (ppb) } & \multirow[b]{2}{*}{ Number of ears examined } & \multicolumn{2}{|c|}{ Number of ears with section Flavic } \\
\hline & & & & Sporulation & Sclerotia \\
\hline \multicolumn{6}{|l|}{2010 crop } \\
\hline $0 \%$ & $1.0 \pm 0.1$ & $356.8 \pm 163.1$ & $550-814$ & $34-55(7.3 \pm 2.4)$ & $3-14(1.4 \pm 1.0)$ \\
\hline $33 \%$ & $7.2 \pm 1.1$ & $11.9 \pm 17.2$ & $763-801$ & $23-59(4.3 \pm 2.7)$ & $6-9(0.9 \pm 0.2)$ \\
\hline $66 \%$ & $11.7 \pm 0.9$ & $3.7 \pm 4.8$ & $765-795$ & $12-34(2.8 \pm 1.4)$ & $1-11(0.7 \pm 0.7)$ \\
\hline $100 \%$ & $13.3 \pm 1.4$ & $61.0 \pm 64.7$ & $651-681$ & $12-39(3.8 \pm 2.0)$ & $2-11(0.9 \pm 0.7)$ \\
\hline \multicolumn{6}{|l|}{2011 crop } \\
\hline $33 \%$ & $0.6 \pm 0.4$ & $22.1 \pm 35.9$ & $403-513$ & $2-11(1.3 \pm 0.9)$ & $1-4(0.5 \pm 0.3)$ \\
\hline $66 \%$ & $3.6 \pm 1.8$ & $11.3 \pm 9.5$ & $506-710$ & $7-10(1.3 \pm 0.2)$ & $2-4(0.5 \pm 0.2)$ \\
\hline $100 \%$ & $9.5 \pm 1.9$ & $9.4 \pm 11.6$ & $695-721$ & $10-16(1.8 \pm 0.4)$ & $4-8(0.9 \pm 0.3)$ \\
\hline \multicolumn{6}{|l|}{2012 crop } \\
\hline $0 \%$ & $1.6 \pm 0.4$ & $78.3 \pm 70.6$ & $449-812$ & $8-21(2.0 \pm 0.7)$ & $1-8(0.6 \pm 0.4)$ \\
\hline $33 \%$ & $9.4 \pm 1.1$ & $0.2 \pm 0.4$ & $852-909$ & $3-5(0.4 \pm 0.1)$ & $0-1(0.04 \pm 0.07)$ \\
\hline $66 \%$ & $12.6 \pm 0.8$ & $0.0 \pm 0.0$ & $921-966$ & $3-14(0.8 \pm 0.6)$ & $1-3(0.2 \pm 0.1)$ \\
\hline $100 \%$ & $13.3 \pm 1.1$ & $3.0 \pm 5.2$ & $838-861$ & $3-15(0.9 \pm 0.8)$ & $1-4(0.2 \pm 0.2)$ \\
\hline
\end{tabular}

a Means \pm standard deviation and ranges based on three replicate plots per irrigation treatment.

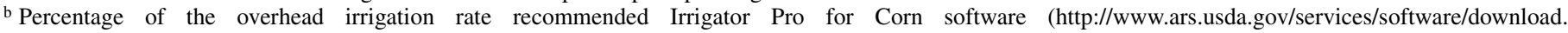
htm?softwareid=248). In 2011, 0\% irrigation treatment did not produce corn ears.

c Percentage of total number of ears examined in parentheses. 
yield for all 3 years and an increase in aflatoxin concentration in 2010 and 2012; however, water availability showed no significant effect on the incidence of section Flavi sporulation or A. flavus $\mathrm{L}$ strain sclerotia. Aflatoxin production in corn is extremely variable due, in part, to its sporadic occurrence among ears and among kernels within an ear, and it is estimated that, in a corn lot containing aflatoxin $\mathrm{B}_{1}$ at $20 \mathrm{ppb}$, only 6 of 10,000 kernels are contaminated $(1,25)$. Fungal structures associated with aflatoxins such as conidial heads and sclerotia likely exhibit a similar sporadic distribution pattern among corn ears and kernels. Therefore, more extensive sampling of corn might be necessary to detect effects of corn drought stress on formation of sclerotia.
The infrequent formation of section Flavi sclerotia in corn ( $0.6 \%$ of ears) supports an earlier study in Georgia by Wicklow et al. (52), who found low densities of A. flavus sclerotia in corn kernels at harvest and in chaff and debris exhausted from the combine harvester. The majority of section Flavi sclerotia from corn in the present study comprised A. flavus, which is consistent with observations that $A$. flavus is the dominant aflatoxigenic species in corn $(11,13)$. Sclerotia from A. flavus L strain were dominant in 2010 and 2011 from the experimental plots whereas sclerotia of A. flavus S strain were dominant in 2012. Aflatoxin contamination of cottonseed in southern Texas and the desert southwestern United States is largely attributed to A. flavus $\mathrm{S}$

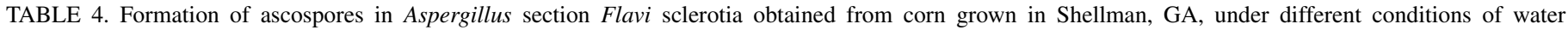
availability

\begin{tabular}{|c|c|c|c|c|}
\hline Irrigation treatment ${ }^{\mathrm{a}}$ & Number of ears & Number of sclerotia incubated ${ }^{b}$ & Species $^{c}$ & $\begin{array}{c}\text { Number of sclerotia forming ascospores } \\
\text { on the surface of nonsterile soil }\end{array}$ \\
\hline \multicolumn{5}{|l|}{2010 crop } \\
\hline \multirow[t]{7}{*}{$0 \%$} & 19 & $1,185(1-565)$ & F-L & 0 \\
\hline & 1 & 176 & F-L & $30(17.0)$ \\
\hline & 1 & 240 & F-L & $32(13.3)$ \\
\hline & 2 & $218(62,156)$ & F-L, F-S & 0 \\
\hline & 1 & 67 & F-L, P & 0 \\
\hline & 2 & $334(124,210)$ & $\mathrm{F}-\mathrm{S}$ & 0 \\
\hline & 1 & 1 & $\mathrm{P}$ & 0 \\
\hline \multirow[t]{12}{*}{$33 \%$} & 11 & $296(1-184)$ & F-L & 0 \\
\hline & 1 & 39 & F-L & $1(2.6)$ \\
\hline & 1 & 229 & F-L & $52(22.7)$ \\
\hline & 1 & 318 & F-L & $1(0.3)$ \\
\hline & 1 & 58 & F-L, F-S & 19 F-L (32.8) \\
\hline & 1 & 274 & $\mathrm{~F}-\mathrm{L}, \mathrm{F}-\mathrm{S}$ & 1 F-L $(0.4)$ \\
\hline & 1 & 500 & $\mathrm{~F}-\mathrm{L}, \mathrm{F}-\mathrm{S}$ & 1 F-L $(0.2)$ \\
\hline & 1 & 6 & F-L, F-S & 0 \\
\hline & 1 & 33 & F-L, P & 0 \\
\hline & 1 & 199 & F-S & 0 \\
\hline & 1 & 21 & A & $13(61.9)$ \\
\hline & 1 & 105 & $\mathrm{~A}$ & $101(96.2)$ \\
\hline \multirow[t]{3}{*}{$66 \%$} & 14 & $488(1-137)$ & F-L & 0 \\
\hline & 1 & 26 & F-L & $9(34.6)$ \\
\hline & 1 & 167 & F-L & $15(9.0)$ \\
\hline \multirow[t]{7}{*}{$100 \%$} & 13 & $261(1-69)$ & F-L & 0 \\
\hline & 1 & 15 & F-L & $1(6.7)$ \\
\hline & 1 & 18 & F-L & $1(5.6)$ \\
\hline & 1 & 95 & F-L & $22(23.2)$ \\
\hline & 1 & 126 & F-L & $22(17.5)$ \\
\hline & 1 & 245 & F-L & $30(12.2)$ \\
\hline & 1 & 282 & F-L & $16(5.7)$ \\
\hline \multicolumn{5}{|l|}{2011 crop } \\
\hline \multirow[t]{3}{*}{$33 \%$} & 6 & $194(7-60)$ & F-L & 0 \\
\hline & 1 & 204 & F-L, F-S & 0 \\
\hline & 1 & 391 & F-L, F-S, P & 1 F-S $(0.3)$ \\
\hline \multirow[t]{2}{*}{$66 \%$} & 7 & $549(1-300)$ & F-L & 0 \\
\hline & 2 & $489(243,246)$ & F-L, F-S & 0 \\
\hline \multirow[t]{4}{*}{$100 \%$} & 16 & $890(3-307)$ & F-L & 0 \\
\hline & 1 & 16 & F-L & $1(6.3)$ \\
\hline & 1 & 70 & F-L & $2(2.9)$ \\
\hline & 1 & 43 & F-L, C & 0 \\
\hline \multicolumn{5}{|l|}{2012 crop } \\
\hline \multirow[t]{6}{*}{$0 \%$} & 2 & $3(1,2)$ & F-L & 0 \\
\hline & 1 & 3 & F-L & $1(33.3)$ \\
\hline & 1 & 183 & F-L, F-S & 4 F-S (2.2) \\
\hline & 1 & 225 & $\mathrm{~F}-\mathrm{L}, \mathrm{F}-\mathrm{S}$ & $3 \mathrm{~F}-\mathrm{S}(1.3)$ \\
\hline & 2 & $393(7,386)$ & F-L, F-S & 0 \\
\hline & 6 & $611(8-329)$ & $\mathrm{F}-\mathrm{S}$ & 0 \\
\hline $33 \%$ & 1 & 197 & F-S & $2(1.0)$ \\
\hline \multirow[t]{2}{*}{$66 \%$} & 3 & $37(4-26)$ & F-L & 0 \\
\hline & 3 & $1,224(20-1024)$ & $\mathrm{F}-\mathrm{S}$ & 0 \\
\hline \multirow[t]{2}{*}{$100 \%$} & 5 & $184(1-83)$ & F-L & 0 \\
\hline & 1 & 46 & F-L & $7(15.2)$ \\
\hline
\end{tabular}

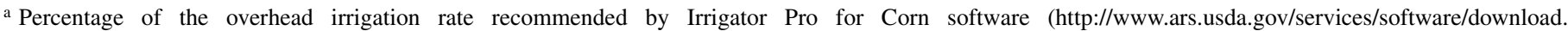
htm?softwareid=248). In 2011, $0 \%$ irrigation treatment did not produce corn ears.

b Total number of sclerotia; range of sclerotium numbers per ear in parentheses.

c Abbreviations: F-L, A. flavus L strain; F-S, A. flavus S strain; P, A. parasiticus; C, A. caelatus; A, A. alliaceus.

${ }^{\mathrm{d}}$ Percentage of sclerotia producing ascospores in parentheses. 
strain, which suggests an adaptation of the fungus to high temperatures and drought $(5,24)$. Although water availability in this study did not have a significant effect on the incidence of $\mathrm{L}$ strain sclerotia, an examination of $\mathrm{S}$ strain sclerotia over the 3-year period showed a strong association with water availability, with $81.5 \%$ of corn ears containing $S$ strain sclerotia occurring in the 0 and $33 \%$ irrigation treatments and no $\mathrm{S}$ strain sclerotia being detected in any of the $100 \%$ irrigation plots. A. parasiticus infrequently infects corn (11) and few ears contained $A$. parasiticus sclerotia, which have been previously reported only from peanut (15). A. alliaceus is commonly isolated from soil (27) and has been reported from onion, fig, wheat, peanut, and pistachio nuts $(7,8,32,40,41)$; however, the species has not been reported in corn and this article also represents the first report of sclerotia from nature.

The formation of ascocarps with viable ascospores in A. flavus sclerotia that were collected from corn and incubated on nonsterile soil in the laboratory demonstrates the potential for sexual reproduction in the field. Ascospore formation in sclerotia was extremely variable among corn ears as well as among sclerotia from individual ears. A. flavus and A. parasiticus might require co-infection of a crop with sexually compatible strains of the opposite mating type, an event whose low probability could account for the infrequent occurrence of ascospore formation in sclerotia. Sweany et al. (46) found a relatively low diversity of vegetative compatibility groups of A. flavus in corn compared with soil isolates and the majority of isolates from corn were MAT1-2. A low infection rate by A. parasiticus in corn might even further reduce the ability of this species to produce fertile sclerotia.

Ascospore formation in A. flavus sclerotia from Shellman differed considerably for each of the 3 years. The 2010 and 2011 corn crops were dominated by A. flavus L strain sclerotia but ascospore formation was much higher in 2010 compared with 2011. The 2012 crop was dominated by A. flavus S strain sclerotia and very few of those sclerotia formed ascospores. Differences in the frequency of ascospore formation might be due to environmental conditions that influence mating during corn infection. In addition, corn is infected by soil populations of A. flavus that serve as a source of primary inoculum and by populations in infected crops that serve as a source of secondary inoculum $(13,50)$. The distribution of mating types and the presence of female sterility factors (29) in either of those two populations might greatly influence the ability of $A$. flavus to mate and produce ascospores. For example, populations of Lobaria pulmonaria often show significant differences in the frequency of MAT1-1 and MAT1-2 genes, and the predominance of one mating type lowers the likelihood of sexual reproduction in those populations (43). Horn et al. (21) postulated that sclerotia serve a dual purpose in the life cycle of $A$. parasiticus by (i) withstanding adverse environmental conditions (unfertilized sclerotia) and (ii) providing for genetic recombination (fertilized sclerotia). Data presented here suggest that the majority of A. flavus sclerotia are not involved in sexual reproduction and, instead, act as resistant structures or produce conidia through sporogenic germination.

Ascocarps and ascospores were not detected in A. flavus sclerotia at corn harvest. In addition, sclerotia retrieved from homothallic A. alliaceus and E. ochrosalmoneum at harvest also did not contain ascospores. However, A. alliaceus and E. ochrosalmoneum sclerotia both readily formed ascospores after laboratory incubation on nonsterile soil, suggesting that sclerotia of homothallic species as well as sclerotia of mated heterothallic A. flavus and $A$. parasiticus require an additional incubation period on soil after dispersal for development of the sexual stage. A. flavus sclerotia from corn in this study were incubated on soil at $30^{\circ} \mathrm{C}$ and $100 \%$ relative humidity but the conditions conducive to ascospore formation in nature, where sclerotia are exposed to daily and seasonal fluctuations in temperature and humidity, are not known. Ascospore formation in E. ochrosalmoneum sclerotia on soil is highly temperature dependent, with an optimum rate of formation at 25 to $30^{\circ} \mathrm{C}$; ascospores are not produced at 15 and $37^{\circ} \mathrm{C}(23)$.

The present study showed that asexual sporulation by $E$. ochrosalmoneum on the conidial heads of A. flavus occurs in corn under field conditions. In culture, E. ochrosalmoneum demonstrates high host specificity for section Flavi in its ability to sporulate on the conidial heads of Aspergillus spp. (20). Horn (12) speculated that E. ochrosalmoneum uses the much taller conidiophores of Aspergillus spp. as a platform for aerial dispersal of conidia. When A. flavus sclerotia from corn were incubated on soil, E. ochrosalmoneum not only sporulated asexually on the surface of sclerotia and on the conidial heads arising from sporogenic germination but also formed ascospore-bearing sclerotia on the surface or within the matrix of A. flavus sclerotia. It is not known whether A. flavus sclerotia were colonized by E. ochrosalmoneum during development on corn or after placement on soil. Internally produced sclerotia of E. ochrosalmoneum could be distinguished from ascocarps of $A$. flavus by the thicker outer wall and by ascospores that are 3.5 to 5.0 by 2.5 to $3.5 \mu \mathrm{m}$, with two longitudinal flanges (38), as opposed to the ascospores of A. flavus, which are 8.0 to 12.5 by 7.5 to $12.0 \mu \mathrm{m}$ and have a single equatorial ridge (18). Although the nature of the relationship between E. ochrosalmoneum and section Flavi has not been elucidated (12,20), the formation of E. ochrosalmoneum sclerotia within the matrix of $A$. flavus sclerotia suggests that parasitism is involved. By forming sexual structures within the larger $A$. flavus sclerotia, E. ochrosalmoneum benefits from any protective and dispersal properties provided by the host sclerotium.

Much remains to be learned about the sexual cycle of heterothallic A. flavus and the contribution of sexuality to genetic diversity in agricultural fields. In this study, a small proportion of $A$. flavus strains of the opposite mating type likely became associ-

TABLE 5. Formation of ascospores in Aspergillus section Flavi sclerotia obtained from corn ears in additional fields (2010)

\begin{tabular}{|c|c|c|c|c|c|}
\hline Field & Location & $\begin{array}{l}\text { Number of } \\
\text { ears }\end{array}$ & $\begin{array}{l}\text { Number of sclerotia } \\
\text { incubated }^{\mathrm{a}}\end{array}$ & Species $^{\mathrm{b}}$ & $\begin{array}{l}\text { Number of sclerotia forming ascospores } \\
\text { on the surface of nonsterile soil }\end{array}$ \\
\hline \multirow[t]{3}{*}{ A } & Randolph County, GA & 1 & 3 & F-L & 0 \\
\hline & & 1 & 72 & F-L & $3(4.2)$ \\
\hline & & 1 & 136 & F-L, F-S & 3 F-L (2.2) \\
\hline B & Terrell County, GA & 1 & 2 & F-L & 0 \\
\hline \multirow[t]{3}{*}{$\mathrm{C}$} & Randolph County, GA & 2 & $8(3,5)$ & F-L & 0 \\
\hline & & 1 & 239 & F-L & $184(77.0)$ \\
\hline & & 1 & 265 & F-L, F-S & 0 \\
\hline \multirow[t]{3}{*}{$\mathrm{D}$} & Edgecombe County, NC & 8 & $253(1-86)$ & F-L & 0 \\
\hline & & 1 & 1 & F-L & $1(100.0)$ \\
\hline & & 1 & 216 & F-L & $7(3.2)$ \\
\hline
\end{tabular}

a Total number of sclerotia; range of sclerotium numbers per ear in parentheses.

b Abbreviations: F-L, A. flavus L strain; F-S, A. flavus S strain.

c Percentage of sclerotia producing ascospores in parentheses. 
ated during infection of corn. However, the development of sclerotia in relation to mating and nuclear fusion is not understood, and additional research is needed to determine whether these initial stages of the sexual process occur in the crop or after dispersal onto soil. Furthermore, the role of soil microbial populations during sexual development and the environmental conditions most conducive to sexual reproduction in nature have not been examined. Natural populations of A. flavus show an evolutionary history of recombination based on patterns of linkage disequilibrium (LD) in the aflatoxin gene cluster (31). In a single generation, progeny from laboratory crosses exhibit crossing over in the aflatoxin gene cluster that results in LD blocks consistent with patterns of LD in natural populations (33). The frequency and patterns of recombination in progeny from naturally produced ascospore-bearing sclerotia remain to be determined.

\section{ACKNOWLEDGMENTS}

This work was partially funded by the North Carolina Cooperative State Research, Education and Extension Service 2008-34500-19396 to I. Carbone. R. A. Olarte was supported by a United States Department of Agriculture National Needs Fellowship. We also thank the National Science Foundation's Dimensions of Biodiversity program for financial support (award number 1046167); T. Walk, M. Schweikert, and J. Childre for their technical assistance; and R. Heiniger for allowing us to sample the North Carolina cornfield.

\section{LITERATURE CITED}

1. Brera, C., De Santis, B., Prantera, E., Debegnach, F., Pannunzi, E., Fasano, F., Berdini, C., Slate, A. B., Miraglia, M., and Whitaker, T. B. 2010. Effect of sample size in the evaluation of "in-field" sampling plans for aflatoxin $\mathrm{B}_{1}$ determination in corn. J. Agric. Food Chem. 58:84818489.

2. Carbone, I., Jakobek, J. L., Ramirez-Prado, J. H., and Horn, B. W. 2007. Recombination, balancing selection and adaptive evolution in the aflatoxin gene cluster of Aspergillus parasiticus. Mol. Ecol. 16:4401-4417.

3. Coley-Smith, J. R., and Cooke, R. C. 1971. Survival and germination of fungal sclerotia. Annu. Rev. Phytopathol. 9:65-92.

4. Cotty, P. J. 1989. Virulence and cultural characteristics of two Aspergillus flavus strains pathogenic on cotton. Phytopathology 78:1250-1253.

5. Cotty, P. J. 1997. Aflatoxin-producing potential of communities of Aspergillus section Flavi from cotton producing areas in the United States. Mycol. Res. 101:698-704.

6. Dorner, J. W. 2005. Biological control of aflatoxin crop contamination. Pages 333-352 in: Aflatoxin and Food Safety. H. K. Abbas, ed. Taylor \& Francis, Boca Raton, FL.

7. Doster, M. A., and Michailides, T. J. 1994. Aspergillus molds and aflatoxins in pistachio nuts in California. Phytopathology 84:583-590.

8. Doster, M. A., and Michailides, T. J. 2007. Fungal decay of first-crop and main-crop figs. Plant Dis. 91:1657-1662.

9. Ehrlich, K. C., Montalbano, B. G., and Cotty, P. J. 2007. Analysis of single nucleotide polymorphisms in three genes shows evidence for genetic isolation of certain Aspergillus flavus vegetative compatibility groups. FEMS Microbiol. Lett. 268:231-236.

10. Garber, R. K., and Cotty, P. J. 1997. Formation of sclerotia and aflatoxins in developing cotton bolls infected by the $\mathrm{S}$ strain of Aspergillus flavus and potential for biocontrol with an atoxigenic strain. Phytopathology 87:940-945.

11. Hill, R. A., Wilson, D. M., McMillian, W. W., Widstrom, N. W., Cole, R. J., Sanders, T. H., and Blankenship, P. D. 1985. Ecology of the Aspergillus flavus group and aflatoxin formation in maize and groundnut. Pages 79-95 in: Trichothecenes and Other Mycotoxins. J. Lacey, ed. John Wiley \& Sons, Chichester, UK.

12. Horn, B. W. 2005. Colonization of wounded peanut seeds by soil fungi: Selectivity for species from Aspergillus section Flavi. Mycologia 97:202217.

13. Horn, B. W. 2007. Biodiversity of Aspergillus section Flavi in the United States: A review. Food Addit. Contam. 24:1088-1101.

14. Horn, B. W., and Dorner, J. W. 1999. Regional differences in production of aflatoxin $\mathrm{B}_{1}$ and cyclopiazonic acid by soil isolates of Aspergillus flavus along a transect within the United States. Appl. Environ. Microbiol. 65:1444-1449.

15. Horn, B. W., Dorner, J. W., Greene, R. L., Blankenship, P. D., and Cole, R. J. 1994. Effect of Aspergillus parasiticus soil inoculum on invasion of peanut seeds. Mycopathologia 125:179-191.
16. Horn, B. W., and Greene, R. L. 1995. Vegetative compatibility within populations of Aspergillus flavus, A. parasiticus, and A. tamarii from a peanut field. Mycologia 87:324-332.

17. Horn, B. W., Greene, R. L., Sobolev, V. S., Dorner, J. W., Powell, J. H., and Layton, R. C. 1996. Association of morphology and mycotoxin production with vegetative compatibility groups in Aspergillus flavus, A. parasiticus, and A. tamarii. Mycologia 88:574-587.

18. Horn, B. W., Moore, G. G., and Carbone, I. 2009. Sexual reproduction in Aspergillus flavus. Mycologia 101:423-429.

19. Horn, B. W., Moore, G. G., and Carbone, I. 2011. Sexual reproduction in aflatoxin-producing Aspergillus nomius. Mycologia 103:174-183.

20. Horn, B. W., and Peterson, S. W. 2008. Host specificity of Eupenicillium ochrosalmoneum, E. cinnamopurpureum and two Penicillium species associated with the conidial heads of Aspergillus. Mycologia 100:12-19.

21. Horn, B. W., Ramirez-Prado, J. H., and Carbone, I. 2009. The sexual state of Aspergillus parasiticus. Mycologia 101:275-280.

22. Horn, B. W., Ramirez-Prado, J. H., and Carbone, I. 2009. Sexual reproduction and recombination in the aflatoxin-producing fungus Aspergillus parasiticus. Fungal Genet. Biol. 46:169-175.

23. Horn, B. W., and Wicklow, D. T. 1986. Ripening of Eupenicillium ochrosalmoneum ascostromata on soil. Mycologia 78:248-252.

24. Jaime-Garcia, R., and Cotty, P. J. 2006. Spatial distribution of Aspergillus flavus and its toxigenic strains on commercial cottonseed from south Texas and its relationship to aflatoxin contamination. Plant Pathol. 55:358-366.

25. Johansson, A. S., Whitaker, T. B., Giesbrecht, F. G., Hagler, W. M., and Young, J. H. 2000. Testing shelled corn for aflatoxin, Part II: Modeling the observed distribution of aflatoxin test results. J. AOAC Int. 83:12701278.

26. Jones, R. K., Duncan, H. E., and Hamilton, P. B. 1981. Planting date, harvest date, and irrigation effects on infection and aflatoxin production by Aspergillus flavus in field corn. Phytopathology 71:810-816.

27. Klich, M. A. 2002. Biogeography of Aspergillus species in soil and litter. Mycologia 94:21-27.

28. Lamb, M., Sorensen, R., Nuti, R. C., Butts, C. L., Faircloth, W. H., Eigenbert, D., and Rowland, D. L. 2011. Agronomic and economic effect of irrigation rate in corn produced in Georgia. Plant Manage. Network. Online publication. doi:10.1094/CM-2011-0721-02-RS

29. Leslie, J. F., and Klein, K. K. 1996. Female fertility and mating type effects on effective population size and evolution in filamentous fungi. Genetics 144:557-567.

30. McAlpin, C. E., and Wicklow, D. T. 2005. Culture media and sources of nitrogen promoting the formation of stromata and ascocarps in Petromyces alliaceus (Aspergillus section Flavi). Can. J. Microbiol. 51:765771 .

31. Moore, G. G., Singh, R., Horn, B. W., and Carbone, I. 2009. Recombination and lineage-specific gene loss in the aflatoxin gene cluster of Aspergillus flavus. Mol. Ecol. 18:4870-4887.

32. Mutegi, C. K., Ngugi, H. K., Hendriks, S. L., and Jones, R. B. 2012. Factors associated with the incidence of Aspergillus section Flavi and aflatoxin contamination of peanuts in the Busia and Homa bay districts of western Kenya. Plant Pathol. 61:1143-1153.

33. Olarte, R. A., Horn, B. W., Dorner, J. W., Monacell, J. T., Singh, R., Stone, E. A., and Carbone, I. 2012. Effect of sexual reproduction on population diversity in aflatoxin production by Aspergillus flavus and evidence for cryptic heterokaryosis. Mol. Ecol. 21:1453-1476.

34. Payne, G. A. 1998. Process of contamination by aflatoxin-producing fungi and their impact on crops. Pages 279-306 in: Mycotoxins in Agriculture and Food Safety. K. K. Sinha and D. Bhatnagar, eds. Marcel Dekker, New York.

35. Payne, G. A., Cassel, D. K., and Adkins, C. R. 1986. Reduction of aflatoxin contamination in corn by irrigation and tillage. Phytopathology 76:679-684.

36. Payne, G. A., Thompson, D. L., Lillehoj, E. B., Zuber, M. S., and Adkins, C. R. 1988. Effect of temperature on the preharvest infection of maize kernels by Aspergillus flavus. Phytopathology 78:1376-1380.

37. Peterson, S. W. 2008. Phylogenetic analysis of Aspergillus species using DNA sequences from four loci. Mycologia 100:205-226.

38. Pitt, J. I. 1979. The Genus Penicillium and its Teleomorphic States Eupenicillium and Talaromyces. Academic Press, London.

39. Ramirez-Prado, J. H., Moore, G. G., Horn, B. W., and Carbone, I. 2008 Characterization and population analysis of the mating-type genes in Aspergillus flavus and Aspergillus parasiticus. Fungal Genet. Biol. 45:1292-1299.

40. Raper, K. B., and Fennell, D. I. 1965. The Genus Aspergillus. Williams \& Wilkins, Baltimore.

41. Riba, A., Mokrane, S., Mathieu, F., Lebrihi, A., and Sabaou, N. 2008. Mycoflora and ochratoxin A producing strains of Aspergillus in Algerian wheat. Int. J. Food Microbiol. 122:85-92.

42. Robens, J., and Cardwell, K. F. 2005. The costs of mycotoxin manage- 
ment in the United States. Pages 1-12 in: Aflatoxin and Food Safety. H. K. Abbas, ed. Taylor \& Francis, Boca Raton, FL.

43. Singh, G., Dal Grande, F., Cornejo, C., Schmitt, I., and Scheidegger, C. 2012. Genetic basis of self-incompatibility in the lichen-forming fungus Lobaria pulmonaria and skewed frequency distribution of mating-type idiomorphs: Implications for conservation. PLoS One 7:e51402.

44. Sobolev, V. S., and Dorner, J. W. 2002. Cleanup procedure for determination of aflatoxins in major agricultural commodities by liquid chromatography. J. AOAC Int. 85:642-645.

45. Sorensen, R. B., Nuti, R. C., and Lamb, M. C. 2010. Yield and economics of shallow subsurface drip irrigation (S3DI) and furrow diking. Plant Manage. Network. Online publication. doi:10.1094/CM-2010-1220-01RS

46. Sweany, R. R., Damann, K. E., and Kaller, M. D. 2011. Comparison of soil and corn kernel Aspergillus flavus populations: Evidence for niche specialization. Phytopathology 101:952-959.

47. Thompson, D. L., Lillehoj, E. B., Leonard, K. J., Kwolek, W. F., and Zuber, M. S. 1980. Aflatoxin concentration in corn as influenced by kernel development stage and postinoculation temperature in controlled environments. Crop Sci. 20:609-612.

48. van Egmond, H. P., and Jonker, M. A. 2005. Worldwide regulations on aflatoxins. Pages 77-93 in: Aflatoxin and Food Safety. H. K. Abbas, ed. Taylor \& Francis, Boca Raton, FL.

49. Wicklow, D. T. 1987. Survival of Aspergillus flavus sclerotia in soil.
Trans. Br. Mycol. Soc. 89:131-134.

50. Wicklow, D. T., and Donahue, J. E. 1984. Sporogenic germination of sclerotia in Aspergillus flavus and A. parasiticus. Trans. Br. Mycol. Soc. 82:621-624.

51. Wicklow, D. T., and Horn, B. W. 1984. Aspergillus flavus sclerotia form in wound-inoculated preharvest corn. Mycologia 76:503-505.

52. Wicklow, D. T., Horn, B. W., Burg, W. R., and Cole, R. J. 1984. Sclerotium dispersal of Aspergillus flavus and Eupenicillium ochrosalmoneum from maize during harvest. Trans. Br. Mycol. Soc. 83:299-303.

53. Wicklow, D. T., Stubblefield, R. D., Horn, B. W., and Shotwell, O. L. 1988. Citreoviridin levels in Eupenicillium ochrosalmoneum-infested maize kernels at harvest. Appl. Environ. Microbiol. 54:1096-1098.

54. Wicklow, D. T., and Wilson, D. M. 1986. Germination of Aspergillus flavus sclerotia in a Georgia maize field. Trans. Br. Mycol. Soc. 87:651653.

55. Wicklow, D. T., Wilson, D. M., and Nelsen, T. C. 1993. Survival of Aspergillus flavus sclerotia and conidia buried in soil in Illinois or Georgia. Phytopathology 83:1141-1147.

56. Willets, H. J. 1971. The survival of fungal sclerotia under adverse environmental conditions. Biol. Rev. 46:387-407.

57. Williams, J. H., Phillips, T. D., Jolly, P. E., Stiles, J. K., Jolly, C. M., and Aggarwal, D. 2004. Human aflatoxicosis in developing countries: A review of toxicology, exposure, potential health consequences, and interventions. Am. J. Clin. Nutr. 80:1106-1122. 